\title{
Khakra gum -A natural source for eco-printing of silk fabric
}

Author for correspondence

\section{MEENU SRIVASTAVA}

Department of Textiles and Apparel Designing, College of Home Science, Maharana Pratap University of Agriculture and Technology, UDAIPUR (RAJASTHAN) INDIA
ABSTRACT : Present research is based on standardization of printing procedure using Khakra gum (gum excrete of Butea monosperma) as dye source for printing silk fabric with selected mordants for mordant printing. Based on the colour strength values, clarity of design, sharpness of design and level of shades two concentration per mordants were selected for optimization of printing procedure on silk fabric and to study its effects on colourfastness properties. Aqueous medium was found suitable for extraction of dye for one hour. A dye material concentration of $2 \%$ and optimum time of dyeing was found 45 minutes for Khakra gum. After printing the Silk fabric with selected concentration of mordants, the samples were dyed with selected concentration of dye. The dyed and printed silk samples were post treated with 5 per cent solution of different fixing agents, Treatment $1\left(\mathrm{~T}_{1}\right)$-Vinegar $\left(\mathrm{CH}_{3} \mathrm{COOH}\right)$, Treatment $2\left(\mathrm{~T}_{2}\right)$ - Alum AlK $\left(\mathrm{SO}_{4}\right)_{2}$, Treatment $3\left(\mathrm{~T}_{3}\right)$-Common salt $(\mathrm{NaCl})$, Treatment $4\left(\mathrm{~T}_{4}\right)$-Lime juice and Treatment $5\left(\mathrm{~T}_{5}\right)$-Sodium carbonate $\left(\mathrm{Na}_{2} \mathrm{CO}_{3}\right)$ for improving colourfastness towards sunlight, washing and crocking.

KEY WORDS: Kesula, Printing, Silk, Standardization, Colourfastness

- HOW TO CITE THIS PAPER : Srivastava, Meenu (2017). Khakra gum -A natural source for ecoprinting of silk fabric. Asian J. Home Sci., 12 (2) : 503-508, DOI: 10.15740/HAS/AJHS/12.2/503-508. 